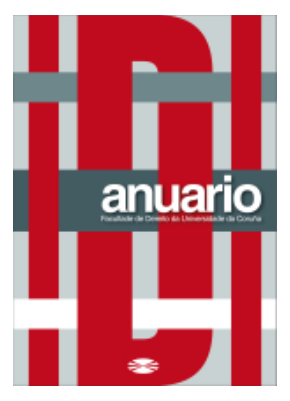

Anuario da Facultade de Dereito da Universidade da Coruña

Vol. 25 (2021), pp. 72-93

ISSNe: 2530-6324 || ISSN: 1138-039X

DOI: https://doi.org/10.17979/afdudc.2021.25.0.8799

\title{
RIDERS, LABORALIDAD PRECARIA O TRADE: UNA VISIÓN JURISPRUDENCIAL
}

\section{RIDERS, PRECARIOUS LABOR OR EDW: A CASE-LAW POINT OF VIEW}

\author{
ÁLVARO HÖHR DE MIGUEL \\ Abogado \\ Doctorando URJC \\ https://orcid.org/0000-0002-5334-3491
}

Recibido: 24/09/2021

Aceptado: 15/11/2021

Resumen: En los últimos tiempos se ha producido una auténtica revolución en las condiciones laborales y en la concepción de prestación de servicios de los denominados Riders. Ciertamente, la jurisprudencia ha ido evolucionando si ben de manera reactiva a las diferentes cuestiones que se iban planteando a la par que evolucionaba este modelo de negocio que se debatía entre la concepción de trabajador como autónomo económicamente dependiente o una laboralidad encubierta. Finalmente, gracias al desarrollo jurisprudencial y a una extraordinaria labor por parte de la Inspección de Trabajo, han conseguido desde agosto de este año la presunción de laboralidad, situación no exenta de detractores entre los propios trabajadores. Analizamos en este artículo la evolución jurisprudencial de esta relación laboral.

Palabras clave: Riders, Glovers, TRADE, Plataformas Digitales, Presunción de Laboralidad.

Abstract: In recent times there has been a real revolution in working conditions and in the conception of the provision of services of the so-called Riders. Certainly, case-law has been evolving if it reactively responds to the different issues that were being raised at the same time that this business model evolved, which was debated between the conception of the worker as economically dependent self-employed or a disguised job. Finally, thanks to the case-law development and extraordinary work on the part of the Labor Inspection, since August of this year they have achieved the presumption of employment, a situation not 
without detractors among the workers themselves. We analyze in this article the evolution of the case-law on this employment relationship.

Keywords: Riders, Glovers, TRADE, Digital Platforms, Presumption of Labor.

Sumario: I. INTRODUCCIÓN. II. ¿QUÉ ES UN RIDER? III. TRADE O PRECARIEDAD LABORAL. IV. UNA VISIÓN JURISPRUDENCIAL. V. CONSOLIDACIÓN DE LA PRESUNCIÓN DE LABORALIDAD. VI. CONTRADICCIÓN ENTRE RIDERS. BIBLIOGRAFÍA.

$* \quad * \quad *$

\section{INTRODUCCIÓN}

El presente estudio versa sobre la evolución en lo que se refiere a la concepción del requisito de dependencia o subordinación laboral de la prestación de servicios que han venido desarrollando los repartidores adscritos a una plataforma digital para el cumplimiento de sus funciones.

Desde la creación del derecho del trabajo hasta el momento actual hemos asistido a una evolución del requisito de dependencia-subordinación. La sentencia del TS de 11 de mayo de 1979 ya matizó dicha exigencia, explicando que "la dependencia no implica una subordinación absoluta, sino sólo la inserción en el círculo rector, organizativo y disciplinario de la empresa" 1 .

Se basará dicho análisis en la evolución que se contiene en diversas sentencias de los juzgados de lo Social, así como de Tribunales Superiores de Justicia y del Tribunal Supremo. En las mismas, se podrá analizar tanto los supuestos de hecho y de derecho como los fallos de las mismas.

A la par de la jurisprudencia, se hace necesario referirse a la legislación que ha ido acompañando esta realidad que, si bien se presta desde largo tiempo atrás, no es menos cierto que ha sufrido un abrupto cambio en su organización con la irrupción de medios digitales y plataformas vía Apps.

Las nuevas tecnologías, la globalización y la descentralización son algunos de los factores contextuales que confluyen y caracterizan el sistema actual $1^{2}$.

Tal como indica la introducción del Real Decreto-ley 9/2021, de 11 de mayo3: "Las tecnologías de la información y la comunicación han tenido la virtualidad de transformar

\footnotetext{
${ }^{1}$ Publicado en el BOE núm. 113, de 12 de mayo de 2021. (Preámbulo).

${ }^{2}$ CRUZ VILLALÓN, J.: "El futuro del trabajo y su gobernanza”, Temas Laborales, núm. 137, 2017, págs. 13 y ss.
} 
en todo el mundo, las relaciones sociales, los hábitos de consumo $\mathrm{y}$, con ello, han generado oportunidades de nuevas formas de negocio que giran, entre otros factores, en torno a la obtención y gestión de datos y a la oferta de servicios adaptados a esta nueva etapa".

Del mismo modo, la formas en que se prestan los servicios han sufrido una importante modificación al aplicarse métodos de cálculo matemáticos y algoritmos los cuales han supuesto una revolución, perfeccionando los recursos y mejorando los resultados. Estas herramientas han tenido la capacidad de mejorar las condiciones de vida de las personas. El ejemplo más cercano donde hemos podido comprobarlo han sido los resultados de una digitalización forzada o acelerada a lo largo de la crisis sanitaria, adecuando servicios y atención sanitaria personalizados a distancia, asegurando el mantenimiento de negocios a través de servicios en línea; o garantizando la continuidad del trabajo a distancia ${ }^{4}$.

\section{II. ¿QUÉ ES UN RIDER?}

Interesa conocer en un primer momento que se entiende por Rider, y cuál ha sido su evolución; desde un trabajador autónomo dependiente a la situación actual en la que se presume la laboralidad en el Real Decreto-ley 9/2021, de 11 de mayo, por el que se modifica el texto refundido de la Ley del Estatuto de los Trabajadores, aprobado por el Real Decreto Legislativo 2/2015, de 23 de octubre, para garantizar los derechos laborales de las personas dedicadas al reparto en el ámbito de plataformas digitales ${ }^{5}$.

La Real Academia de la Lengua Española define al Rider como un "distribuidor de productos que actúa sin la autorización del fabricante y al margen de su red oficial de distribución". Esta acepción dista de la realidad de la concepción que tenemos de esta figura como repartidores ágiles de productos solicitados a través de una app o simplemente vía internet.

Proviene, por otro lado, de la expresión inglesa de "ciclista" entre otros. Esta acepción es la que nos viene a la cabeza nada más escuchar dicho sustantivo: Un ciclista con una mochila a la espalda que reparte comida o productos a domicilio. Sin embargo, no somos conscientes del entramado que conlleva en cuanto a su relación laboral con quién suministra los productos y con quien los solicita.

En un principio, a estos trabajadores se les presumía una condición de independencia total frente a la empresa o empresas en las que prestaban sus servicios, entendiéndose que, el riesgo y ventura de su éxito o fracaso en el desempeño de sus funciones, y por tanto en su remuneración, dependía únicamente de ellos.

\footnotetext{
${ }^{3}$ Real Decreto-ley 9/2021, de 11 de mayo, por el que se modifica el texto refundido de la Ley del Estatuto de los Trabajadores, aprobado por el Real Decreto Legislativo 2/2015, de 23 de octubre, para garantizar los derechos laborales de las personas dedicadas al reparto en el ámbito de plataformas digitales.

${ }^{4}$ CAVAS MARTÍNEZ, F.: "Breves apuntes para una regulación multinivel del trabajo en plataformas digitales", Revista de Derecho Social, núm. 87, 2019, págs. 66 y ss.

${ }^{5}$ Publicado en el BOE núm. 113, de 12 de mayo de 2021.
} 
Ciertamente, se consideraba este tipo de trabajo como un complemento salarial para personas jóvenes o eventualmente sin empleo, que de manera autónoma prestaban estos servicios de repartos a través de estas nuevas formas de empleo vinculadas al trabajo a través de plataformas digitales.

La realidad fue haciendo que los Rider prestaran sus servicios en un operador u otro casi en exclusiva, convirtiéndose en trabajadores autónomos económicamente dependientes, (en adelante TRADE).

Por todo ello, podemos llegar a la definición inicial de que un Rider es aquel trabajador económicamente dependiente que presta sus servicios de reparto a domicilio por sus propios medios recibiendo más del $75 \%$ de toda su facturación de un solo operador.

\section{TRADE O PRECARIEDAD LABORAL}

"Las nuevas tecnologías han convulsionado las fronteras tradicionales entre el trabajo subordinado y el autónomo, afectando profundamente a su separación de acuerdo con la identificación de sus elementos esenciales"6.

La revolución digital 4.0 y la situación recientemente vivida por la pandemia Covid-19 han cambiado sustancialmente las formas de consumo de todos, y especialmente las relacionadas con los hábitos de compra y distribución.

El trabajo a través de plataformas digitales de servicios supone una enorme transformación del modelo de producción y de las relaciones de trabajo.

Esto ha hecho que, desde que proliferaron las diferentes plataformas a las que se adscribían los trabajadores que ejercían las funciones de reparto, la presunción de laboralidad no ha sido pacifica en la concepción de esta figura, denostada por unos, y entendidas como una oportunidad para otros.

Las propias plataformas de servicios han marcado una repercusión clave en las condiciones sobre las que el servicio debe prestarse. Este modelo de negocio se encuadra en la libertad de empresa y en la elección de la descentralización del proceso productivo. No obstante, no se hace uso de una externalización al modo tradicional, mediante una contrata o subcontrata entre la empresa principal y una empresa contratista, que asume tanto la realización de una parte del proceso productivo con sus propios trabajadores asumiendo igualmente el riesgo y ventura del mismo. Las plataformas han elegido un formato de externalización del servicio íntegra y segmentada en tareas individuales muy acotadas y de muy corta duración. Además, no se organiza con una o varias empresas contratistas para que asuman una parte concreta del servicio sino, como crowdsourcing,

\footnotetext{
${ }^{6}$ GOERLICH PESET, J. M.: “¿Repensar el derecho del trabajo? Cambios tecnológicos y empleo”, Gaceta Sindical, núm. 27, 2016, págs. 173-190.
} 
con un llamamiento abierto en red y una variedad de trabajadores registrados como autónomos ${ }^{7}$.

Quizás, la escasa garantía que el derecho laboral ha aportado en sus inicios a esta forma de prestación de servicio, apartándose de su consustancial carácter tuitivo, ha sido el detonante para llegar a una regulación más exhaustiva de la misma.

Bajo el pretexto de reducir los costes laborales, se han buscado fórmulas cuyo objeto era eludir por parte de este sector del manto protector que el ordenamiento garantiza ${ }^{8}$.

De esta forma, "la interferencia de autónomos en el ciclo productivo de una plataforma proveedora de un servicio que actúe a modo de empresa principal, parece una construcción jurídica que encubre una prestación de servicios subordinada" 9 .

Es más que apropiado mencionar varios conceptos, que la profesora Fernández Docampo expone, para conocer dónde comienza a inclinarse la balanza ante la precariedad laboral vs la concepción inicial como TRADE: "Muchas de las plataformas comparten cierto oscurantismo a la hora de exteriorizar al público algunos de sus requisitos de utilización, lo cual, más allá de suscitar los lógicos recelos de sus eventuales destinatarios, contrasta, y mucho, con una serie de iniciativas internacionales que propugnan precisamente lo contrario".

Por un lado, la Recomendación núm. 198 OIT, de 15 de junio de 2006, sobre la relación de trabajo, en la que queda visible la importancia de conocer con claridad sus criterios identificadores para poder accionar sus efectos protectores.

Por otro lado, es clave a nivel Comunitario, mencionar el Dictamen del Comité Económico y Social Europeo sobre el tema "Nuevas tendencias del trabajo autónomo: el caso específico del trabajo autónomo económicamente dependiente" 10 el cual hace un estudio casi monográfico de las tendencias más recientes que afectan al trabajo parasubordinado.

Es de reseñar que esta categoría, que podríamos llamar intermedia, entre el clásico trabajador asalariado y la del autónomo o parasubordinado, no existe en todos los Estados que conforman la Unión Europea, algo que sería de gran interés para mejorar la protección de esta categoría de trabajadores, sin tener que verse abocados los asimilados a

${ }^{7}$ OTERO GURRUCHAGA, C.: "El complicado encaje de los trabajadores de la economía colaborativa en el Derecho Laboral. Nuevos retos para las fronteras de la laboralidad", Derecho de las Relaciones Laborales, núm. 1, 2018, págs. 61-74.

${ }^{8}$ BAYLOS GRAU, A.: La "huida" del Derecho del Trabajo: tendencias y límites a la deslaboralización, "AA. VV" (Coord. ALARCÓN CARACUEL, M.R. y MIRÓN HERNÁNDEZ, M.a. M.), El trabajo ante el cambio de siglo: un tratamiento multidisciplinar, Marcial Pons, Barcelona, 2000, págs. 37 y ss.

9 CABEZA PEREIRO, J.: "Los derechos del trabajador autónomo ante la nueva economía", Revista de Derecho Social, núm. 86, 2019, págs. 64 y ss.

${ }^{10}$ Dictamen del Comité Económico y Social Europeo sobre el tema "Nuevas tendencias del trabajo autónomo: el caso específico del trabajo autónomo económicamente dependiente", (Dictamen de iniciativa). 2011/C $18 / 08$. 
los asalariados, dotando a los trabajadores de una mayor seguridad jurídica y además mayor flexibilidad al empleador.

Dentro de los países que recogen la figura del trabajador económicamente dependiente encontramos reglamentaciones sustancialmente diferentes, si bien entendemos que las realidades económicas y sociales son muy distintas en los países que la contemplan. No obstante, entendemos que el reto, pues no es tarea fácil aunar posturas, de una regulación unitaria o al menos igualitaria para todos los países europeos del trabajo parasubordinado o del trabajador económico dependiente, al igual que pasa con el dependiente, afianzaría este modelo de prestación de servicios y lo dotaría de una aceptación jurídicamente más segura para aquellos países que aún no disfrutan de esta figura y para evitar la disparidad de criterios en los que ya es una realidad.

Una armonización comunitaria de los regímenes jurídicos profesionales en la Unión, comenzando por la propia definición europea del trabajo autónomo económicamente dependiente, no es cosa fácil.

Ciertamente, no son pocas las situaciones en las que el empresario, con el fraudulento objetivo de eludir la correcta aplicación del Derecho Laboral o de la Seguridad Social, califica de trabajo autónomo a prestaciones laborales que no lo son. Desgraciadamente abundan los casos en los que el trabajador se ve forzado a convertirse en trabajador autónomo económicamente dependiente no de forma voluntaria, sino obedeciendo a una externalización productiva o ante la extinción de contratos laborales de la empresa en la que presta sus servicios para la "viabilidad" de la misma.

Teniendo como referencia los datos europeos disponibles respecto de la magnitud del trabajo autónomo ${ }^{11}$, comprobamos que en 2007, en cada uno de los Estados miembros, los trabajadores autónomos que no empleaban ningún asalariado constituían como mínimo el $50 \%$ del total de los trabajadores autónomos. En algunos Estados dicho porcentaje era incluso más elevado (el $70 \%$ o más). Es el caso de la República Checa, Lituania, Portugal, Eslovaquia y el Reino Unido.

Teniendo en cuenta los cambios económicos y sociales que explican la aparición de nuevas formas de trabajo autónomo y la experiencia de los países que han regulado dichas formas de prestación de servicios, llegamos a la conclusión que una parte muy significativa de "own account workers" trabaja en situación de dependencia económica.

En el Libro Verde de la Comisión De Las Comunidades Europeas, consagrado a la modernización del Derecho laboral, publicado en $2006^{12}$, cuya finalidad es plantear un debate público en la UE sobre cómo modernizar el Derecho laboral para sostener el objetivo de la Estrategia de Lisboa de crecer de manera sostenible, con más y mejores empleos, la Comisión Europea señalaba que: "el trabajo por cuenta propia constituye igualmente una manera de afrontar la reconversión, reducir los costes directos o indirectos de la mano de obra y gestionar los recursos de manera más flexible en

\footnotetext{
${ }^{11}$ A la vista de las distintas definiciones de este concepto que utiliza Eurostat.

${ }^{12}$ Libro Verde - Modernizar el Derecho laboral para afrontar los retos del siglo XXI (COM (2006) 708 final).
} 
circunstancias económicas imprevistas. También revela un modelo mercantil de empresas orientadas al suministro de servicios que realizan proyectos completos para sus clientes. En muchos casos puede resultar de una decisión, tomada libremente, de trabajar de forma independiente a pesar de un nivel de protección social menor a cambio de un control más directo de las condiciones de empleo y de remuneración".

Sólo un número limitado de Estados miembros reconocen el concepto de trabajador autónomo económicamente dependiente como tal, si bien, como hemos comentado anteriormente cada uno mantiene sus particularidades. Esta categoría intermedia de trabajadores, que se sitúa entre el trabajo autónomo y el asalariado, acaba por crear nuevas formas de empleo, con un alcance y un contenido que son distintos en función de los países.

Es el caso, en particular, de Alemania, Austria, España, Italia, Portugal y el Reino Unido. En Italia, la noción de "parasubordinación" se aplica a los trabajadores contratados mediante un "contrato de colaboración coordinada y continua", así como a los que participan en un "contrato de colaboración de proyecto".

En el Reino Unido existe la categoría de "worker", que difiere de la de "employee". El "worker" se distingue del asalariado "employee" en que desempeña su trabajo sin encontrarse bajo la autoridad del empleador.

En Austria existen formas contractuales específicas reconocidas por la normativa en las que se pueden encontrar signos de una toma en consideración general del trabajo autónomo económicamente dependiente. Se trata, en concreto, del caso de los "freie Dienstverträge" (contratos libres de servicios). Los trabajadores contratados mediante este tipo de contratos se distinguen de los asalariados por el hecho de que, a pesar de que muy a menudo trabajan para una sola persona y según un calendario determinado, no están encuadrados en una relación de subordinación.

En Alemania existe la noción de "arbeitnehmerähnliche Person" (persona asimilada a un trabajador). Esta categoría de trabajadores, que la normativa laboral considera distinta de la de asalariado, designa a aquellas personas que, en el marco de un contrato mercantil o de prestación de servicios, desempeñan su trabajo personalmente, sin recurrir a la contratación de asalariados y de forma que más del $50 \%$ del volumen de negocio proviene de un único cliente.

El ejemplo más reciente, y más logrado, de definición de trabajo autónomo económicamente dependiente es el de España. El Estatuto del trabajador autónomo, aprobado en 2007, define a los trabajadores autónomos económicamente dependientes en función de varios criterios. "Son aquéllos que realizan una actividad económica o profesional a título lucrativo y de forma habitual, personal, directa y predominante para una persona física o jurídica, denominada cliente, del que dependen económicamente por percibir de él, al menos, el $75 \%$ de sus ingresos por rendimientos de trabajo y de 
actividades económicas o profesionales. Este régimen es incompatible con una sociedad civil o mercantil" 13 .

El profesor Perulli ${ }^{14}$ considera así que: "la dependencia económica del trabajador no puede establecerse más que si la organización productiva de este último depende de la actividad de su cliente. Con otras palabras, el trabajador debe encontrarse en una situación de incapacidad de acceder al mercado a causa de que su organización productiva (lo que incluye especialmente el material y la tecnología empleada) esté totalmente dirigida hacia la satisfacción de las necesidades de un único cliente”.

En el artículo 20 ET se recoge que, las facultades empresariales pueden ser ejercidas por medio de la gestión algorítmica del servicio o de las condiciones de trabajo a través de una plataforma digital, que son, por lo tanto, los activos clave y esenciales de la $\operatorname{actividad}^{15}$.

El contenido de la Directiva 2019/1152, de 20 de junio, relativa a unas condiciones laborales transparentes y previsibles en la $\mathrm{UE}^{16}$, parecía que seguía la línea del contexto de la economía digital.

En su Exposición de Motivos y concretamente en el punto 4, se advierte de la incertidumbre jurídica que pueden sufrir algunas de las nuevas formas de empleo derivadas de la digitalización, haciendo de la información completa y accesible uno de los elementos esenciales de protección social ${ }^{17}$.

A escala comunitaria, la reglamentación de las condiciones de trabajo de los agentes comerciales autónomos muestra que las normas del mercado interior pueden acercarse a determinados aspectos del Derecho laboral. Para garantizar la protección mínima de los agentes comerciales independientes en sus relaciones con sus poderdantes, la Directiva $86 / 653 / \mathrm{CEE}^{18}$, contiene disposiciones relativas, entre otras cosas, al pago de su remuneración; las condiciones de transformación de los contratos de duración determinada en contratos de duración indeterminada; y la indemnización por el perjuicio causado por la terminación de un contrato.

\footnotetext{
${ }^{13}$ Véase el artículo 11 de la Ley española de 11 de julio de 2007 sobre el Estatuto del trabajo autónomo.

14 PERULLI, A.: “Travail économiquement dépendant/parasubordination: les aspects juridiques, sociaux et économiques", (Trabajo económicamente dependiente/parasubordinación: aspectos jurídicos, sociales y económicos), Informe para la Comisión Europea, 2003.

${ }^{15}$ Real Decreto-ley 9/2021, de 11 de mayo, por el que se modifica el texto refundido de la Ley del Estatuto de los Trabajadores, aprobado por el Real Decreto Legislativo 2/2015, de 23 de octubre, para garantizar los derechos laborales de las personas dedicadas al reparto en el ámbito de plataformas digitales.

${ }^{16}$ Publicado en DOUE núm. 186, de 11 de julio de 2019, páginas 105 a 121.

${ }^{17}$ FERNÁNDEZ DOCAMPO, M. B.: “Análisis Casuístico De La Prestación De Servicios De Los Riders De Glovo A Través Del Contenido Fáctico De Las Resoluciones Judiciales”, Temas Laborales, núm. 151, 2020, págs. 157-173.

18 PERULLI, A.: "Economically dependent / quasi-subordinate (parasubordinate) employment: legal, social and economic aspects", 2002.
} 
Este oscurantismo en el que han estado envueltas las relaciones laborales en las plataformas digitales, quizás buscado por estas, dificulta conocer con suficiente detalle la relación entre la plataforma y el prestador y la organización del servicio en sí, salvo a través de los hechos declarados probados en las sentencias de instancia que finalmente ha concluido en la presunción de laboralidad en las relaciones entre estos.

Únicamente un análisis en conjunto, nos permite entender y por tanto defender con criterios sólidos la existencia de una relación laboral o de una prestación de servicios autónoma.

Podemos afirmar que es la falta de transparencia de las plataformas digitales, concretamente en relación a sus algoritmos para la asignación de pedidos, lo que hace desconfiar de la aparente independencia del trabajador frente a las mismas.

Al conocer dichos algoritmos, los criterios de asignación de envíos, la regularidad de los mismos, la distribución horaria de la prestación y aún la propia evaluación que el cliente hace del servicio quedan al descubierto en las distintas sentencias que analizaremos a continuación la realidad de la precariedad laboral al que están sometidos estos trabajadores y a los niveles de dependencia y ajenidad en los que se desarrolla su trabajo.

Por todo ello, las notas que más polémica generan en la relación entre las plataformas y sus repartidores son los criterios de dependencia y ajenidad.

Antes de entrar de lleno en las sentencias que dan una visión general jurisprudencial de estas relaciones, podemos afirmar que los algoritmos aplicados por empresas como Glovo, Deliveroo, etc., hacen que el trabajador se encuentre en una situación absolutamente subordinada, no teniendo capacidad alguna de independencia en los aspectos que atañen a su desarrollo laboral, llegando incluso a ser expulsados "de facto" por el sistema, si no cumplen los objetivos previstos por los mismos, lo más parecido a un despido disciplinario, y subyugados a un horario o disponibilidad horaria casi permanente si quieren obtener una remuneración que les permita obtener una rentabilidad mínima por su trabajo.

En cualquier caso, no cabe justificar la vulneración de derechos sociales como ventaja competitiva de manera que las nuevas formas de empleo se conviertan en empleo precario o economía sumergida ${ }^{19}$. Todo ello sin olvidar que la flexibilidad que caracteriza el empleo del futuro, cuando es voluntaria, tiene sin duda, implicaciones positivas ${ }^{20}$.

\section{UNA VISIÓN JURISPRUDENCIAL}

\footnotetext{
${ }^{19}$ MOLINA NAVARRETE, C.: "Derecho y trabajo en la era digital ¿"revolución industrial 4.0” o "economía sumergida 3.0" ?, “AA. VV”, El futuro del trabajo que queremos, 2017, págs. 403-424.

${ }^{20} \mathrm{La}$ capacidad del trabajador de concretar el momento de ejecución de la prestación y de rechazar tareas, permite compatibilizar su actividad profesional con formación, responsabilidades familiares u otro trabajo típico o a tiempo parcial, facilita la inserción laboral de colectivos con especiales dificultades o problemas de salud o discapacidad y favorece la creación de empleo y la disminución del desempleo. Véase SUAREZ CORUJO B.: "El sistema de seguridad social ante la "uberización" de la economía", en "AA. VV"., $L a$ gestión del cambio laboral en la empresa, Thomson Reuters Aranzadi, Cizur Menor, 2017, págs. 103 y ss.
} 
Con el presente análisis pretendemos únicamente delimitar los finos límites entre el trabajo autónomo y el subordinado sino conseguir diferenciarlos de una manera que nos resulte tan traumática ${ }^{21}$.

Para ello, nos centraremos en el estudio de la plataforma Globo a través de las numerosas sentencias de tribunales de lo social que se han ido sucediendo en el tiempo.

Los objetivos de estas plataformas son, por una parte, impulsar productos de los establecimientos de restauración que contraten sus servicios, por un lado, promocionando productos de los restaurantes que contraten sus servicios, gestionar telemáticamente los pedidos de consumidores finalizando con la venta de los productos en nombre del restaurante; y, por otro lado, prestar el servicio de recogida de los pedidos en el restaurante y de entrega en el domicilio o lugar designado por el cliente.

"Para el reparto y distribución de comida preparada de restaurantes no celebra formalmente contratos de trabajo sino contratos de prestación de servicios con mensajeros o repartidores" 22 .

De cara al registro en la plataforma como repartidor, a los que la propia empresa califica de colaboradores $^{23}$, los potenciales glovers o riders, necesitan superar y acreditar una serie de requisitos, unos informativos y otros de carácter material.

En cuanto a los requisitos informativos, también llamado entrevista informativa, "se les explica el funcionamiento de la aplicación y la mecánica del reparto"24. Suele desarrollarse en varias sesiones en las que igualmente se incluye información sobre "el funcionamiento del negocio empresarial" 25 .

En ocasiones, tales sesiones reciben el nombre de "sesiones de formación (...) por parte de Glovo" 26 , con una duración de varias horas, referida a la utilización de la App, horarios y zonas los encargos.

El segundo requisito consiste en la solicitud de acreditación por parte de los futuros riders de su alta en el Régimen Especial de Trabajadores Autónomos, así como el desembolso de 20 euros para hacer frente a los gastos de asesoría ${ }^{27}$.

${ }^{21}$ CRUZ VILLALÓN, J.: "El concepto de trabajador subordinado frente a las nuevas formas de empleo", Revista De Derecho Social, núm. 83, 2018, págs. 13 y ss.

${ }^{22}$ SSJS núm. 6 de Valencia, de 1 de junio de 2018, y núm. 31 de Barcelona, de 11 de junio de 2019.

${ }^{23}$ S. del Juzgado de lo Social no 1 de Gijón núm. 61/2019 de 20 febrero (HP SÉPTIMO) y STSJ de Asturias (Sala de lo Social) núm. 1818/2019 de 25 julio (HP SEGUNDO). El término "colaborador" también aparece así expresamente en la web https://glovoapp.com/es/glovers.

${ }^{24}$ S. del Juzgado de lo Social no 1 de Gijón núm. 61/2019 de 20 febrero (HP SÉPTIMO) y STSJ de Asturias (Sala de lo Social) núm. 1818/2019 de 25 julio (HP SEGUNDO).

${ }^{25}$ S. del Juzgado de lo Social no 24 de Barcelona núm. 202/2019 de 21 mayo (HP CUARTO)

y S. del Juzgado de lo Social no 24 de Barcelona núm. 205/2019 de 29 mayo (HP CUARTO).

${ }^{26}$ S. del Juzgado de lo Social no 1 de Madrid núm. 130/2019 de 4 abril (HP OCTAVO).

${ }^{27}$ S. del Juzgado de lo Social n ${ }^{\text {o }} 1$ de Gijón núm. 61/2019 de 20 febrero (HP SÉPTIMO) y

STSJ de Asturias (Sala de lo Social) núm. 1818/2019 de 25 julio (HP SEGUNDO). 
"Únicamente cuando concurren estos requisitos se firma el contrato de colaboración, y se les proporciona una dirección de correo y la correspondiente contraseña, pudiendo entonces empezar con el reparto" 28 , y adquirir desde ese momento la condición de glovers, también conocidos en este caso como los riders de Glovo.

En ocasiones, resulta evidente que el vínculo formalizado entre el glover y Glovo ha sido un "contrato de prestación de servicios profesionales para la realización de recados, pedidos, o micro tareas como trabajador autónomo" ${ }^{29}$. En otras, la relación entre plataforma y prestador de servicios "contrato para la realización de actividad profesional como trabajador autónomo económicamente dependiente" 30 .

En ningún caso, de los estudiados hasta este momento, se ha celebrado un contrato de trabajo ni el mero reconocimiento de la existencia de una relación laboral entre Glovo y sus repartidores.

En definitiva, podemos destacar dos puntos básicos que deben señalarse en lo que se refiere a la contratación de un potencial rider por parte de Glovo:

- Por una parte, la necesidad de superar una serie de requisitos que le exige la plataforma, algunos de ellos con contenido formativo. Es decir, existe una cierta orientación profesional empresarial al futuro prestador del servicio que ella misma publicita en su plataforma.

- Por otro, la obligación unilateral de aceptar, también por parte de la plataforma, las condiciones que regirán su relación contractual con el trabajador, sin que se aprecie la existencia de ningún espacio libre abierto a la negociación hacen pensar que estamos cada vez más alejados de una relación con autonomía propia y más cerca de una situación laboral de dependencia y subordinación.

Tanto la necesidad de garantizar la aceptación de las condiciones, así como la obligación de tener que superar los requisitos que marca Glovo para obtener la condición de repartidor, aleja el desempeño de una actividad autónoma y lo aproxima al de una laboral, más allá que esta actividad requiera una cualificación de escasa complejidad ${ }^{31}$.

Atendiendo a los criterios de asignación de trabajo que quedan expuestos en los distintos fundamentos de hecho de las sentencias estudiadas, los denominados repartos, resultan los siguientes:

\footnotetext{
${ }^{28}$ S. del Juzgado de lo Social no 1 de Gijón núm. 61/2019 de 20 febrero (HP SÉPTIMO).

${ }^{29}$ S. del Juzgado de lo Social no 39 de Madrid núm. 284/2018 de 3 septiembre (HP PRIMERO).

${ }^{30}$ S. del Juzgado de lo Social no 17 de Madrid núm. 12/2019 de 11 enero (HP PRIMERO), S. del Juzgado de lo Social no 24 de Barcelona núm. 202/2019 de 21 mayo (HP SEXTO) y STSJ de Asturias (Sala de lo Social) núm. 1818/2019 de 25 julio (HP SEGUNDO).

${ }^{31}$ FERNÁNDEZ DOCAMPO, M. B.: “Análisis Casuístico De La Prestación De Servicios De Los Riders De Glovo A Través Del Contenido Fáctico De Las Resoluciones Judiciales”, Temas Laborales, núm. 151, 2020, págs. 157-173.
} 
En primer lugar; el repartidor debe mantenerse activo dentro su franja horaria. Seguidamente, el tipo de aceptación del reparto puede ser automática o manual -la aceptación automática significa que es la plataforma la que asigna el pedido- "pudiendo ser rechazado por el repartidor", -mientras que en la aceptación manual- "es el repartidor el que selecciona el reparto de entre los disponibles" 32 .

En segundo lugar; la plataforma debe conocer su disponibilidad, esto es, que el rider indique y la empresa conozca si se encuentra libre, en fase final de entrega de un producto o, incluso, si así lo solicita, en fase de espera de la recepción de un producto.

Finalmente, Glovo debe conocer la proximidad del trabajador al lugar de recogida y posterior entrega ${ }^{33}$.

El algoritmo o fórmula matemática empleada por la plataforma ha sido diseñado para alcanzar el menor coste posible en la prestación del servicio, para lo cual se tiene en cuenta, entre otros factores, el sistema de evaluación de repartidores ${ }^{34}$ ya sea por el establecimiento o por el cliente final que califica la entrega en función del tiempo invertido, calidad del mismo...

Únicamente cuando el repartidor acepta el pedido entra en contacto directo con el cliente siendo en ese momento cuando el trabajador recibe toda la información necesaria para la correcta realización del servicio ${ }^{35}$.

Una de las evidencias de la existencia de subordinación económica es que, tanto de la política de pagos por los servicios prestados, así como como en lo relativo a la remuneración de los repartidores, es exclusivamente gestionado por la empresa. Concretamente, el precio por cada servicio de reparto lo determina la plataforma de forma orientativa y así se lo hace llegar al cliente cada vez que inicia una solicitud.

En la configuración del precio, la plataforma atiende a variables tales como tiempo y distancia, e incluye el IVA. De no ser posible calcular las referidas variables, Glovo se limita a realizar una estimación, también con IVA. En cualquiera de los casos únicamente al finalizar el transporte el repartidor recibe de parte de la plataforma la comunicación del precio final ${ }^{36}$.

El hecho de que sea unilateralmente Glovo la que fija tanto los precios de los servicios ofertados y la remuneración de los riders, más allá de configurar otra prueba de la unilateralidad en el establecimiento de las condiciones contractuales, constituye, una clara evidencia de subordinación económica característica de las relaciones laborales.

${ }^{32}$ S. del Juzgado de lo Social no 1 de Gijón núm. 61/2019 de 20 febrero (HP NOVENO).

${ }^{33}$ Todos estos criterios en STSJ de Asturias (Sala de lo Social) núm. 1818/2019 de 25 julio (HP SEGUNDO).

${ }^{34}$ S. del Juzgado de lo Social no 33 de Madrid núm. 53/2019 de 11 febrero (HP CUARTO). y S. del Juzgado de lo Social n ${ }^{\circ} 1$ de Madrid núm. 134/2019 de 4 abril (HP SEGUNDO).

${ }^{35}$ S. del Juzgado de lo Social no 24 de Barcelona núm. 202/2019 de 21 mayo (HP TERCERO).

${ }^{36}$ S. del Juzgado de lo Social no 1 de Madrid núm. 130/2019 de 4 abril (HP SEXTO). 
Pero es que, a mayor abundamiento, los riders no reciben sus honorarios de los clientes de dicha plataforma, sino que la mercantil, previa facturación al cliente por ésta, algo que constituye otra importante seña de relación laboral.

Los trainers son una figura que se encuentra en este tipo de plataformas siendo los encargados de los repartidores. Ellos son los responsables de explicar a los nuevos riders las características y el proceso de prestación del servicio, así como la conexión a la aplicación que deben emplear, la recepción de ofertas, su aceptación y el protocolo a seguir en caso de presentarse dificultades, así como el trato que debe dispensarse a restaurantes y clientes ${ }^{37}$.

Una vez incorporados se les proporciona material informativo en el que se les invita a presentarse frente a los usuarios como parte de la empresa, además, se les explican ciertas restricciones en el desempeño de sus funciones y lo más importante, las consecuencias que tiene el rechazo continuado de pedidos, siendo la más relevante el no garantizarle un mínimo de estos y, como consecuencia de ello, la repercusión en su remuneración llegando incluso a prescindir de sus servicios ${ }^{38}$.

En lo referente a los horarios de trabajo de los riders, y con independencia de la libertad y flexibilidad que se indica en la web, los fundamentos de hecho contenidos en las sentencias estudiadas, muestran la existencia de cierta organización empresarial de la que emanan órdenes e instrucciones.

En primer lugar, periódicamente, un par de veces por semana, están sometidos al cumplimiento de dos franjas horarias, previa selección, en las que se comprometen a trabajar $^{39}$.

En segundo lugar, la selección antes indicada, habilitadas en la aplicación por parte de la plataforma, así como la elección de días y horas de prestación de servicios, dependerá de la puntuación personal que cada repartidor haya obtenido por los establecimientos y clientes previamente $^{40}$.

Finalmente, una de las causas que penalizan su puntuación es no tener activa la aplicación en el "inicio del bloque horario reservado para ofrecer sus servicios" 41 . Esto se da pese a no existir ninguna obligación de estar disponibles, "pudiendo conectarse a la aplicación cuando quieran" 42 , pues "son ellos los que deciden libremente el momento de inicio y finalización de su jornada" 43 .

\footnotetext{
${ }^{37}$ SJS núm. 31 de Barcelona, de 11 junio de 2019.

${ }^{38}$ La STSJ de Madrid, de 27 de enero de 2020, y S. del Juzgado de lo Social no 24 de Barcelona núm. 205/2019 de 29 mayo (HP TERCERO).

${ }^{39}$ S. del Juzgado de lo Social no 33 de Madrid núm. 53/2019 de 11 febrero (HP TERCERO) y STSJ de Madrid (Sala de lo Social) núm. 1155/2019 de 27 noviembre (HP SEGUNDO).

${ }^{40} \mathrm{~S}$. del Juzgado de lo Social n ${ }^{\circ} 1$ de Gijón núm. 61/2019 de 20 febrero (HP OCTAVO) y STSJ de Asturias (Sala de lo Social) núm. 1818/2019 de 25 julio (HP SEGUNDO).

${ }^{41}$ STSJ de Asturias (Sala de lo Social) núm. 1818/2019 de 25 julio (HP SEGUNDO).

${ }^{42}$ S. del Juzgado de lo Social no 24 de Barcelona núm. 205/2019 de 29 mayo (HP QUINTO).

${ }^{43}$ S. del Juzgado de lo Social no 39 de Madrid núm. 284/2018 de 3 septiembre (HP SEXTO).
} 
Como hemos visto anteriormente, no es menos cierto que los riders, tienen libertad para aceptar pedidos, aunque el hecho de no aceptarlos, hace que el algoritmo que asigna pedidos "les penaliza desde el momento en que la plataforma les llama menos" 44 .

Genera asimismo no poca confusión que la titularidad de los medios de prestación de los servicios ofertados a través de la App y el régimen de asunción de riesgos. Todos ellos conforman elementos propios de una relación laboral, pero igualmente de una prestación autónoma.

Así las cosas, de cara a efectuar los repartos, tal como se desprende de varias sentencias, los glovers disponen de una "caja con cinchas para llevarla a la espalda identificada con la imagen corporativa de Glovo, de un soporte para la caja, de un soporte para el móvil, un cargador portátil, una bolsa térmica, una tarjeta "bankable" y de un chubasquero. Por tal material deben abonar 10 euros más IVA, así como una fianza de 60 euros que les es devuelta una vez finalizada la colaboración con la empresa siempre que el material esté en buen estado" $"$.

La asignación de dicha tarjeta bancaria a los riders se realiza con el objeto de que adquieran productos, siempre que se necesario, a diferentes proveedores sin acuerdo comercial previo, pero siendo una obligación por parte del repartidor el justificar su uso ${ }^{46}$.

Es también conocido que el medio de transporte de empleen los riders para el desarrollo de su trabajo deben ser aportados por ellos mismos ya se bicicleta o motocicleta, los que utilicen esta última tienen un plus en su retribución, pero no acaba aquí la aportación de medios que hace el trabajador. Igualmente, deben proveer el teléfono móvil así como asumir los gastos de su funcionamiento ${ }^{47}$.

Es de reseñar que únicamente los repartidores son los que deben responder del buen fin del servicio que prestan, asumiendo por tanto el riesgo y ventura de la gestión. En tal grado es así que, sólo recibirán la contraprestación económica del ejercicio de sus funciones en el caso que el cliente reciba el pedido de forma satisfactoria y así lo haga saber mediante la puntuación que otorga a través de la aplicación. Estos trabajadores llegan a asumir frente a sus clientes los daños o perdidas que durante el transporte sufran los productos o mercancías.

Como se ha indicado "ut supra" hay trabajadores que acompañan, además, a otro rider un día para conocer la mecánica de funcionamiento y la aplicación en la práctica, a modo de formación en paralelo, antes de la suscripción del contrato ${ }^{48}$.

\footnotetext{
${ }^{44}$ S. del Juzgado de lo Social no 1 de Madrid núm. 130/2019 de 4 abril (HP DÉCIMO).

${ }^{45}$ S. del Juzgado de lo Social ${ }^{\circ} 1$ de Gijón núm. 61/2019 de 20 febrero (HP DUODÉCIMO) y STSJ de Asturias (Sala de lo Social) núm. 1818/2019 de 25 julio (HP SEGUNDO).

${ }^{46}$ S. del Juzgado de lo Social no 1 de Madrid núm. 130/2019 de 4 abril (HP SEGUNDO Y SEXTO).

${ }^{47}$ S. del Juzgado de lo Social no 1 de Madrid núm. 128/2019 de 3 abril (HP CUARTO), S. del Juzgado de lo Social ${ }^{\circ} 1$ de Madrid núm. 130/2019 de 4 abril (HP CUARTO) y S. del Juzgado de lo Social no 1 de Madrid núm. 134/2019 de 4 abril (HP CUARTO).

${ }^{48}$ SJS núm. 5 de Valencia, de 10 de junio de 2019.
} 
La forma de asignar los servicios de reparto y mensajería por parte de la plataforma a cada rider, los cuales de forma ineludible han de estar geolocalizados, no es más que otra característica de su sometimiento a una organización empresarial.

Para empezar, el trabajo se adjudica mediante un algoritmo o fórmula matemática creado por la empresa que busca la mejor relación entre pedido-repartidor de manera que se ajusten al máximo los costes.

La situación relativa dentro de esta fórmula está directamente relacionada con la puntuación que tengan asignada el trabajador por establecimiento y cliente final de la que se encarga la empresa Glovo de gestionar. Esta puntuación es recibida tomando como elementos la rapidez de la entrega y la inexistencia de incidentes entre otros. Asimismo, su sistema retributivo, es el típico que podemos encontrar en una relación de subordinación, en la que los empleados no fijan las tarifas por los servicios que prestan ni se encargan de cobrar a los clientes de forma que tampoco elaboran las facturas a Glovo por los servicios realizados con el fin de cobrar sus honorarios.

Una vez dado de alta en la aplicación de la plataforma, reciben vía email la confirmación de su situación de repetidores de Glovo. Por otro lado, es en ese momento donde se les comunidad las zonas y o puntos de espera de cada área que le ha sido asignada, así como obligatoriedad de comunicar la disponibilidad semanal que disponen ${ }^{49}$.

Las nuevas tecnologías, la globalización y la descentralización, tal como indica el profesor Cruz Villalón, son algunos de los factores contextuales que confluyen y caracterizan el sistema actual ${ }^{50}$.

\section{CONSOLIDACIÓN DE LA PRESUNCIÓN DE LABORALIDAD}

Como se ha podido comprobar a lo largo de este estudio, "bajo este modelo de negocio aparecen auténticas relaciones laborales por cuenta ajena que se presentan con fórmulas de trabajo precario y de subempleo" 51 .

La diferenciación entre falsos autónomos, trabajadores asalariados y TRADE se enmarca en una delgada línea que no es fácil de delimitar, es por ellos que debe acudirse para su discernimiento a no pocas interpretaciones y revisiones doctrinales ${ }^{52}$.

A fecha de 22 de julio de 2019, el Juzgado de lo Social de Madrid emite el siguiente fallo que por su claridad reproducimos en su literalidad: "Que, estimando la demanda interpuesta por la Tesorería General de la Seguridad Social, contra ROOFOODS SPAIN

\footnotetext{
${ }^{49}$ SSJS núm. 6 Valencia, de 1 de junio de 2018 y núm. 19 de Madrid, de 22 de julio de 2019.

${ }^{50}$ CRUZ VILLALÓN, J.: "El futuro del trabajo y su gobernanza”, Temas Laborales, núm. 137, 2017, págs. 13 y ss.

${ }^{51}$ MONEREO PÉREZ, J. L. y LÓPEZ INSUA, B.M: "Las difusas fronteras entre el trabajo asalariado y por cuenta propia. Riders y plataformas digitales de nuevo a examen en la doctrina de los Tribunales Superiores de Justicia”, Revista de jurisprudencia laboral, núm. 4, 2020.

${ }^{52}$ STSJM 40/2020, de 17 de enero, Sala de lo Social.
} 
S.L. y las personas físicas indicadas en el encabezamiento, con personación de los sindicatos CCOO y UGT, declaro, con los efectos legales correspondientes, que los trabajadores codemandados estaban sujetos a una relación laboral con ROOFOODS SPAIN S.L. en el tiempo en el que prestaron respectivamente sus servicios en el período que abarca el acta de liquidación, condenando a la indicada sociedad a estar y pasar por ello" 53 .

Por su parte, las pretensiones de la empresa Deliveroo consisten en que sus trabajadores se mantengan en el modelo contractual de trabajadores autónomos económicamente dependientes, argumentando que de otra forma ningún trabajador tiene la libertad de poder decidir si presta o no sus servicios de manera unilateralmente. De esta forma, la empresa hace hincapié en que son los riders quienes decidían igualmente las preferencias horarias para el desempeño de sus funciones.

A mayor abundamiento, la empresa esgrime que, en base a las decisiones indicadas en el párrafo anterior por el trabajador unilateralmente adoptadas no puede elaborar un horario ni calendario definido. Por otro lado, refiere que la geolocalización de los trabajadores no atiende a un mecanismo de control por su parte sino a un medio necesario para que los pedidos lo puedan gestionar aquellos riders más cercanos al restaurante que los cubre. Asimismo, inciden en la falta de poder disciplinario de Roofoods Spain SL ya que, de manera directa, en ningún momento ha adoptado ni aplicado medidas o sanciones disciplinarias sobre estos prestadores de servicios.

En lo referente a la ajenidad de los frutos del trabajo, se alega que en ningún caso existe (puesto que los riders percibirían el fruto de su trabajo, consistiendo éste en la cantidad recibida de Roofoods Spain SL; no pudiendo considerarse que el consumidor final fuese cliente del rider).

Tampoco se daría la supuesta ajenidad en los medios pues son los riders los titulares de los mismos. De la misma forma, se opone la empresa a que estos trabajadores no asuman el riesgo y ventura de sus operaciones ya que son ellos mismos los que ofrecen sus servicios en el mercado de las plataformas digitales.

No cabe duda que en el ámbito laboral el concepto de dependencia tiene un significado amplio que no se refiere únicamente al ámbito económico, sino que va más allá extendiéndose a la sujeción del trabajador a la dirección y control por parte del empresario.

De ahí que el artículo 1 de la tan citada Ley 20/2007 ${ }^{54}$ del Estatuto del trabajo autónomo, (en adelante LETA), se refiera al TRADE como persona que realiza su actividad fuera del ámbito de dirección y organización de otra persona.

\footnotetext{
${ }^{53}$ Juzgado de lo Social $\mathrm{n}^{\circ} 19$ de Madrid 510/2018 de 22 de julio.

${ }^{54}$ Publicado en el BOE núm. 166, de 12 de julio de 2007.
} 
La dependencia, elemento clave para incardinar al trabajador como por cuenta ajena o propia, lo marca el algoritmo o fórmula matemática de la propia empresa, que es la que por su propio funcionamiento da el carácter de dependencia del trabajador a la empresa.

Por su parte, "el trabajador por cuenta propia es aquél que desarrolla su actividad con total autonomía (falta de ajenidad) y con criterios organizativos independientes de cualquier estructura jerárquica empresarial (ausencia de dependencia o subordinación). Esta aparente separación conceptual es relativamente sencilla mientras no se traslade a la práctica" 55 .

El artículo 11.1 LETA define al TRADE como: "aquéllos que realizan una actividad económica o profesional a título lucrativo y de forma habitual, personal, directa $\mathrm{y}$ predominante para una persona física o jurídica, denominada cliente, del que dependen económicamente por percibir de él, al menos, el 75 por ciento de sus ingresos por rendimientos de trabajo y de actividades económicas o profesionales".

En definitiva: el trabajo ha de ser personal, prestado en régimen de dependencia económica mediante un contrato de prestación de servicios y con ausencia de subordinación jurídica. Es en este punto donde más uso fraudulento surgen en la figura del TRADE, pues no pocas empresas emplean dicha figura contractual para imponer sus condiciones de forma unilateral y poner en práctica la dirección y control de los trabajadores que "de facto" dependen de ella.

Es un elemento característico del TRADE la plena autonomía, desarrollando su actividad con criterios propios, si bien estas tienen un límite en lo referente a su poder de decisión, ya que obtiene el $75 \%$ de sus ingresos de una sola empresa que deja de ser competidora para ser quien recibe sus servicios.

A tenor de lo analizado anteriormente están presentes los caracteres propios de una relación laboral por cuenta ajena, al darse la existencia de:

- asiduidad.

- retribución con regularidad.

- dirección y control por parte del empresario.

- no asunción del riesgo y ventura del negocio.

- carácter personalísimo de la prestación del servicio.

Como ya indicara el profesor Monereo: "Los trabajadores que no pueden ser calificados como asalariados, pero que se encuentran en una situación de dependencia económica

\footnotetext{
${ }^{55}$ MONEREO PÉREZ, J. L. y LÓPEZ INSUA, B.M: “Las difusas fronteras entre el trabajo asalariado y por cuenta propia. Riders y plataformas digitales de nuevo a examen en la doctrina de los Tribunales Superiores de Justicia", Revista de jurisprudencia laboral, núm. 4, 2020.
} 
frente a un empresario principal, deben poder beneficiarse de los derechos sociales propios de esta dependencia" 56 .

Unos meses después llegó la Sentencia no 805/2020 de 25 de septiembre de 2020 del Pleno de la Sala de lo Social del Tribunal Supremo (rec. 4746/2019), sobre la consideración de los repartidores de la compañía Glovo como falsos autónomos, en la cual contempla a la empresa más que una mera intermediaria, basándose, entre otras cosas, en que "ha establecido medios de control que operan sobre la actividad y no solo sobre el resultado mediante la gestión algorítmica del servicio" 57 , por medio de "una función de coste-beneficio que busca la mejor combinación posible pedido-repartidor que minimice la suma de costes" 58 .

Según la sentencia, a pesar de que el rider esté dispuesto a realizar el reparto en una zona asignada dentro de un horario que, en principio él mismo elige, y no está supeditado a mantenerse siempre disponible en dicha franja horario esta supuesta libertad no deja de ser una entelequia ya que, si en algún momento el trabajador rechaza un pedido, pierde la garantía de que obtenga un número mínimo de pedidos que le supongan unos ingresos suficientes. Puede llegar incluso la plataforma a prescindir de sus servicios. No sólo puede recibir una penalización por la puntuación que reciba de restaurantes y clientes, sino que el propio algoritmo de la plataforma lo relega a último lugar si no garantiza su disponibilidad y eficiencia a la hora de realizar sus servicios.

También establece que se da una sumisión tacita en lo referente a la dirección y control por parte de Deliveroo ya que de no cumplir las instrucciones que la empresa indica el trabajador sufrirá diversas penalizaciones como hemos expuesto en el párrafo anterior.

La Jurisprudencia ha ido evolucionando y ha pasado de considerar a los trabajadores de las plataformas digitales trabajadores autónomos económicamente dependientes, a una visión cada vez más orientada a la dependencia de los mismos y por tanto la sentencia reconoce el carácter laboral de la relación.

El Consejo de Ministros aprobó el Real Decreto-ley 9/2021 de 11 de mayo que garantiza los derechos laborales aquellos trabajadores que se dedican al reparto en el ámbito de las plataformas digitales, tras el acuerdo alcanzado el 10 de marzo, si bien será de aplicación desde el 12 de agosto, entre el Ministerio de Trabajo y Economía Social y las organizaciones sindicales y empresariales.

La finalidad de este Real Decreto ley es la concreción de la información en todos los ámbitos del desarrollo del trabajo en las plataformas digitales de cara no solo al trabajador

\footnotetext{
${ }^{56}$ MONEREO PÉREZ, J. L. y LÓPEZ INSUA, B.M: "Las difusas fronteras entre el trabajo asalariado y por cuenta propia. Riders y plataformas digitales de nuevo a examen en la doctrina de los Tribunales Superiores de Justicia”, Revista de jurisprudencia laboral, núm. 4, 2020.

${ }^{57}$ Sentencia $n^{\circ} 805 / 2020$ de 25 de septiembre de 2020 del Pleno de la Sala de lo Social del Tribunal Supremo (rec. 4746/2019) Fundamento de derecho vigésimo primero.

${ }^{58}$ Sentencia $\mathrm{n}^{\circ}$ 805/2020 de 25 de septiembre de 2020 del Pleno de la Sala de lo Social del Tribunal Supremo (rec. 4746/2019) Antecedente de hecho cuarto.
} 
sino a sus representantes, así como la forma en la que se regula en este caso concreto la relación por cuenta ajena.

Modifica el artículo 64 añadiendo un nuevo párrafo d) a su apartado 4, en el que se reconoce el derecho del comité de empresa a ser informado por la empresa de los parámetros, reglas e instrucciones en los que se basan los algoritmos o sistemas de inteligencia artificial que afectan a la toma de decisiones que pueden incidir en las condiciones de trabajo, el acceso y mantenimiento del empleo, incluida la elaboración de perfiles.

El texto refundido de la Ley del Estatuto de los Trabajadores, aprobado por el Real Decreto Legislativo 2/2015, de 23 de octubre, queda modificado como sigue:

Se introduce una nueva letra d) en el artículo 64.4, con la siguiente redacción:

“d) Ser informado por la empresa de los parámetros, reglas e instrucciones en los que se basan los algoritmos o sistemas de inteligencia artificial que afectan a la toma de decisiones que pueden incidir en las condiciones de trabajo, el acceso y mantenimiento del empleo, incluida la elaboración de perfiles" ${ }^{59}$.

Finalmente, la Disposición adicional vigesimotercera es clave en la resolución del asunto que tratamos pues otorga presunción de laboralidad en el ámbito de las plataformas digitales de reparto.

Por aplicación de lo establecido en el artículo 8.1, se incluye en el ámbito de esta ley la actividad de las personas que prestan servicios remunerados relacionados con el reparto de mercancías a través de una plataforma digital. En este caso, dicha plataforma, debe tener una organización que de forma directa o indirecta ejerza la dirección y control sobre el trabajador mediante cálculos matemáticos o algorítmicos.

No cabe la menor duda que la labor realizada por la Inspección de Trabajo y Seguridad Social ha sido esencial para que en las sentencias citadas se encuentren los avances desde una inicial postura de ajenidad en la prestación de servicios a finalmente, la presunción de laboralidad de las prestaciones de servicios en plataformas digitales de reparto culminando con la STS 805/2020, de 25 de septiembre.

\section{CONTRADICCIÓN ENTRE RIDERS}

Si bien queda acreditada a través de las sentencias y de manera sustantiva en el Real Decreto-ley 9/2021, no son pocos, paradójicamente los riders disconformes con que se les considere personal laboral.

En primer lugar, en una encuesta realizada por la plataforma de reparto a domicilio Deliveroo, el $92 \%$ de los repartidores encuestados considera que operan como

${ }^{59}$ Art. 64. 4, D) texto refundido de la Ley del Estatuto de los Trabajadores, aprobado por el Real Decreto Legislativo 2/2015, de 23 de octubre. 
autónomos ${ }^{60}$. En esta encuesta se ha realizado de forma anónima a más de 2.500 repartidores con los que colabora la compañía en España siendo respondida por cerca de 2.100 de los colaboradores.

Algunas de las conclusiones de dicha encuesta son la siguientes:

- $\quad$ Sorprendentemente, más del $80 \%$ de los riders que trabajan para Deliveroo no se sienten representados ni identificados por la llamada Ley Rider, propuesta por el Ministerio de Trabajo, y manifiestan su preocupación por el futuro de sus empleos, ya que la presunción de laboralidad puede poner en peligro sus puestos de trabajo.

- Con los datos recopilados en el presente estudio, algo más del $90 \%$ de los riders, manifiestan cómo la preocupación más importante es el efecto que esta ley puede tener en sus ingresos, así como que el efecto final en las plataformas pueda reducir su operatividad en diferentes ciudades incrementando la competencia en el desarrollo del trabajo.

- $\quad$ Por otro lado, el $79 \%$ de los riders encuestados creen que dejará a muchos de ellos sin trabajo. Otras opiniones mayoritarias exponen que no representa a los riders (66\%), llevándolos a tener peores condiciones (44\%).

- $\quad$ Por último, únicamente un 5\% de los empleados de estas plataformas creen que esta Ley es imprescindible, bajando aún más el porcentaje cuando se cuestiona si es completa en sus términos.

- $\quad$ Estos datos resultan especialmente preocupantes cuando el 95\% de los riders indica que tiene a su cargo a más de una persona, teniendo un $75 \%$ de ellos a cargo a familias con hijos, padres, hermanos o similar.

Con todo lo expuesto un porcentaje amplio de los repartidores opinan que si finalmente acaban teniendo la condición de laborales no lograrán obtener los ingresos que les nos necesarios para sus necesidades. De esta forma más de la mitad de ellos muestran preocupación y desazón por su futuro.

Como muestra final, únicamente el $2,5 \%$ de ellos se encuentran a favor plenamente de esta nueva regulación.

Una vez en aplicación el Real Decreto-ley 9/2021 si hacemos una reflexión "de lege ferenda" no debería zanjarse a relación con la presunción de laboralidad ya que ni todos los trabajadores ni todos los empresarios se encuentran "cómodos" con dicha presunción.

Dado que el Derecho Laboral está vivo y por su carácter tuitivo, debe estar atento a las necesidades de los agentes sociales. Por ello entendemos que, como punto de partida, esta presunción que ahora otorga debería ser más flexibles en ulteriores cambios legislativos $\mathrm{o}$, incluso, ser objeto de negociación en convenios colectivos.

Todo ello en aras de evitar un paternalismo que acabe con toda flexibilidad laboral para el empresario y el trabajador. Para uno supondría una traba a la hora de hacer eficiente su negocio y al segundo porque por circunstancias personales no desee un trabajo

${ }^{60} \mathrm{https://es.deliveroo.news/news/deliveroo-riders-ley.html} \mathrm{(23} \mathrm{marzo} \mathrm{2021)}$ 
subordinado siendo el económicamente dependiente la figura contractual que por diversos motivos le sea más favorable.

En palabras de Florentino Eguaras: "Concebimos el derecho como un sistema de ordenación social que parte de la racionalidad y se acepta mayoritariamente. La base de tal sistema es la identidad de la persona libre y autónoma con capacidad de organizarse en defensa de sus intereses. El derecho es una objetivación reafirmada socialmente capaz de defender las relaciones jurídicas que son vínculos de derechos y obligaciones.

Donde sólo hay derechos sin obligaciones, o deberes sin derechos no existe una sociedad jurídica, sino la implantación unilateral de los intereses de unos sobre otros.

Por eso el paternalismo no tiene cabida en el derecho porque aquel supone la unilateralidad sin deberes. El derecho es facultad y deber, mientras que el paternalismo es concesión sin derecho a exigir, ni deber para otorgar. Esta es la diferencia esencial entre el paternalismo y el derecho.

El paternalismo otorga, pero ni reconoce ni mantiene, en tanto que lo jurídico reconoce y exige, bilateraliza las relaciones y las impregna de potencialidad para exigir su respeto y cumplimiento, e implica la abstención del tercero frente al derecho subjetivo, llegando a proporcionar al titular del derecho los instrumentos de la exigibilidad mediante los cauces idóneos para el cumplimiento. La evolución social se mide por la implantación en la sociedad de los mecanismos jurídicos para la conformación de las relaciones desde la proyección del derecho y su publicitación con mecanismos reales de tutela, en la esfera de lo público y de lo privado.

No hay sitio para la benevolencia o condescendencia en lo jurídico pues donde hay derecho hay facultades y deberes" 61 .

\section{BIBLIOGRAFÍA}

BAYLOS GRAU, A.: "La "huida" del Derecho del Trabajo: tendencias y límites a la deslaboralización”, en "AA. VV”. (Coord. ALARCÓN CARACUEL, M.R. y MIRÓN HERNÁNDEZ, M. ${ }^{\mathrm{a}}$. M.), "El trabajo ante el cambio de siglo: un tratamiento multidisciplinar", Marcial Pons, Barcelona, 2000, pp. 37 ss.

CABEZA PEREIRO, J.: "Los derechos del trabajador autónomo ante la nueva economía", Revista de Derecho Social, núm. 86, 2019, págs. 64 y ss.

CAVAS MARTÍNEZ, F.: "Breves apuntes para una regulación multinivel del trabajo en plataformas digitales", Revista de Derecho Social, núm. 87, 2019, págs. 66 y ss.

\footnotetext{
${ }^{61}$ EGUARAS MENDIRI, F.: "Paternalismo Y Derecho Laboral". Jurisdicción social: Revista de la Comisión de lo Social de Juezas y Jueces para la Democracia, núm. 222, 2021, págs. 12-29.
} 
CRUZ VILLALÓN, J.: "El futuro del trabajo y su gobernanza”, Temas Laborales, núm. 137, 2017, págs. 13 y ss.

CRUZ VILLALÓN, J.: "El concepto de trabajador subordinado frente a las nuevas formas de empleo", Revista De Derecho Social, núm. 83, 2018, págs. 13 y ss.

EGUARAS MENDIRI, F.: "Paternalismo Y Derecho Laboral". Jurisdicción social: Revista de la Comisión de lo Social de Juezas y Jueces para la Democracia, núm. 222, 2021, págs. 12-29.

FERNÁNDEZ DOCAMPO, M. B.: “Análisis Casuístico De La Prestación De Servicios De Los Riders De Glovo A Través Del Contenido Fáctico De Las Resoluciones Judiciales", Temas Laborales, núm. 151, 2020, págs. 157-173.

GOERLICH PESET, J. M.: “¿Repensar el derecho del trabajo? Cambios tecnológicos y empleo", Gaceta Sindical, núm. 27, 2016, págs. 173-190.

MOLINA NAVARRETE, C.: "Derecho y trabajo en la era digital ¿"revolución industrial 4.0" o "economía sumergida 3.0" ?, en "AA. VV"., El futuro del trabajo que queremos. 2017. Págs. 403-424.

MONEREO PÉREZ, J. L. y LÓPEZ INSUA, B.M: “Las difusas fronteras entre el trabajo asalariado y por cuenta propia. Riders y plataformas digitales de nuevo a examen en la doctrina de los Tribunales Superiores de Justicia”. Revista de jurisprudencia laboral, Número 4/2020.

OTERO GURRUCHAGA, C.: "El complicado encaje de los trabajadores de la economía colaborativa en el Derecho Laboral. Nuevos retos para las fronteras de la laboralidad", Derecho de las Relaciones Laborales, núm. 1, 2018, págs. 61-74.

PERULLI, A.: "Economically dependent / quasi-subordinate (parasubordinate) employment: legal, social and economic aspects". 2002.

PERULLI, A.: "Travail économiquement dépendant/parasubordination: les aspects juridiques, sociaux et économiques", (Trabajo económicamente dependiente/parasubordinación: aspectos jurídicos, sociales y económicos), Informe para la Comisión Europea, 2003.

SUAREZ CORUJO B.: "El sistema de seguridad social ante la "uberización" de la economía", en "AA. VV"., La gestión del cambio laboral en la empresa, Thomson Reuters Aranzadi, Cizur Menor, 2017, págs. 103 y ss. 